
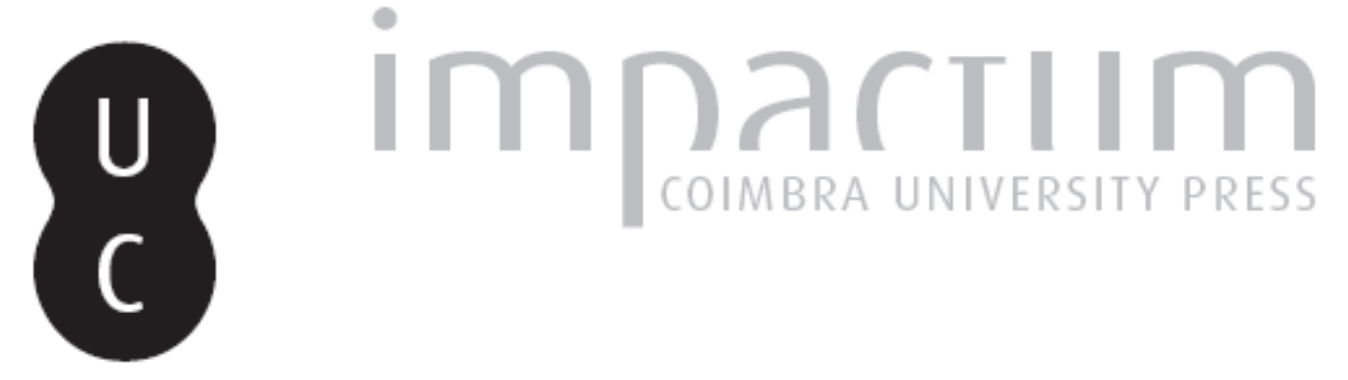

\title{
Estudo de limiares críticos de chuva deflagradores de deslizamentos no Município de São José dos Campos/SP (Brasil)
}

\author{
Autor(es): $\quad$ Mendes, Rodolfo Moreda; Valerío Filho, Mario; Bertoldo, Mathilde \\ Aparecida; Silva, Marlon Ferreira da \\ Publicado por: Associação Portuguesa de Riscos, Prevenção e Segurança; Imprensa \\ da Universidade de Coimbra \\ URL \\ persistente: \\ URI:http://hdl.handle.net/10316.2/38061 \\ DOI: \\ DOI:http://dx.doi.org/10.14195/1647-7723_22_8
}

Accessed : $\quad$ 26-Apr-2023 14:18:44

A navegação consulta e descarregamento dos títulos inseridos nas Bibliotecas Digitais UC Digitalis, UC Pombalina e UC Impactum, pressupõem a aceitação plena e sem reservas dos Termos e Condições de Uso destas Bibliotecas Digitais, disponíveis em https://digitalis.uc.pt/pt-pt/termos.

Conforme exposto nos referidos Termos e Condições de Uso, o descarregamento de títulos de acesso restrito requer uma licença válida de autorização devendo o utilizador aceder ao(s) documento(s) a partir de um endereço de IP da instituição detentora da supramencionada licença.

Ao utilizador é apenas permitido o descarregamento para uso pessoal, pelo que o emprego do(s) título(s) descarregado(s) para outro fim, designadamente comercial, carece de autorização do respetivo autor ou editor da obra.

Na medida em que todas as obras da UC Digitalis se encontram protegidas pelo Código do Direito de Autor e Direitos Conexos e demais legislação aplicável, toda a cópia, parcial ou total, deste documento, nos casos em que é legalmente admitida, deverá conter ou fazer-se acompanhar por este aviso.

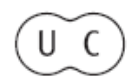




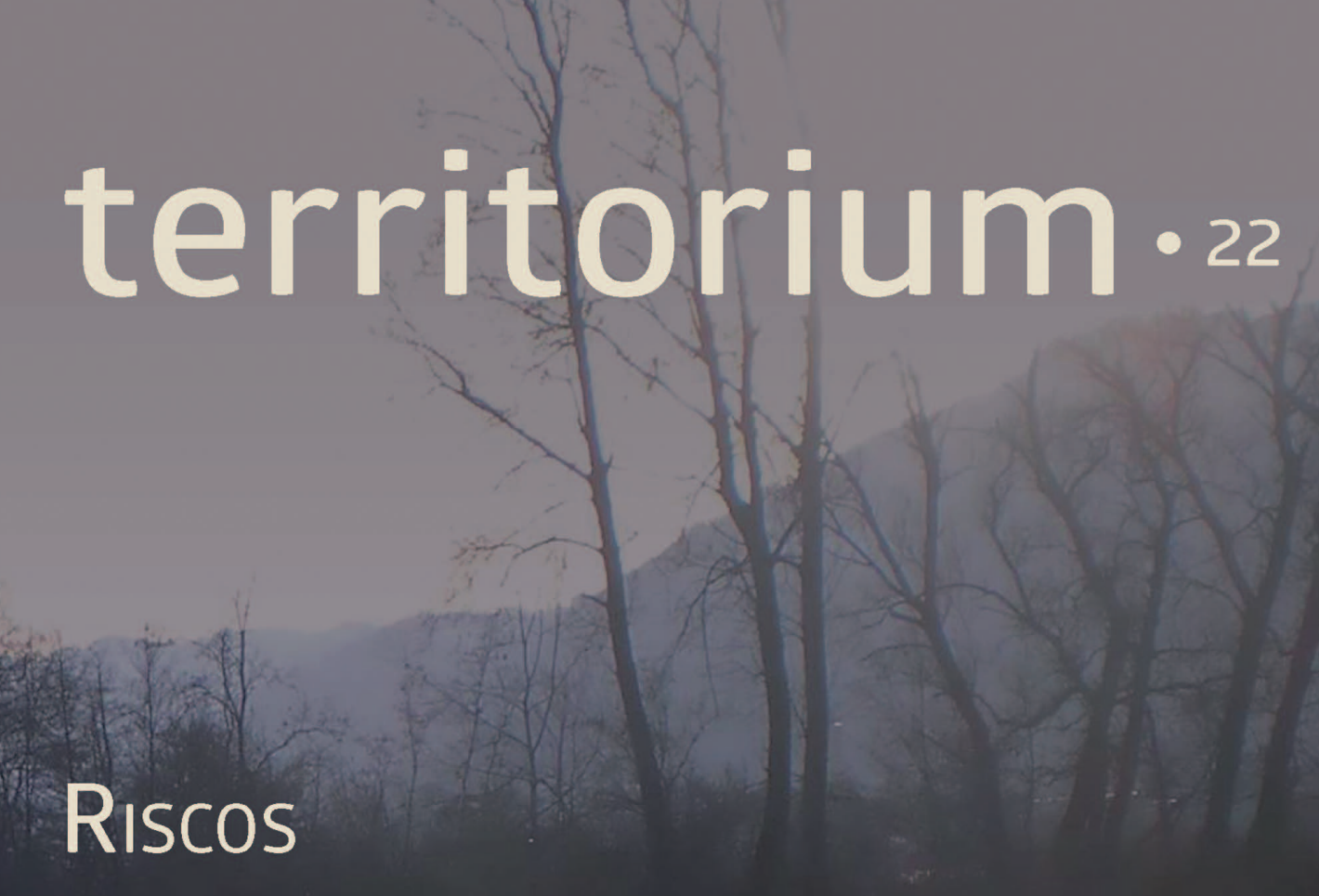

\section{TERRITÓRIOS DE CONVERGÊNCIA}

- Imprensa da Universidade de Coimbra Associação Portuguesa de:Riscos, Prevenção e Segurança 


\title{
ESTUDO DE LIMIARES CRÍTICOS DE CHUVA DEFLAGRADORES DE DESLIZAMENTOS NO MUNICÍPIO DE SÃO JOSÉ DOS CAMPOS/SP (BRASIL)*
}

\section{STUDY OF CRITICAL THRESHOLDS OF LANDSLIDES TRIGGERED BY RAINFALL IN THE MUNICIPALITY OF SÃO JOSÉ DOS CAMPOS/SP (BRAZIL)}

\author{
Rodolfo Moreda Mendes \\ Centro Nacional de Monitoramento e Alertas de Desastres Naturais-CEMADEN, Brasil \\ rodolfo.mendes@cemaden.gov.br \\ Mario Valerío Filho \\ Universidade do Vale do Paraíba-UNIVAP, Brasil \\ mvalerio@univap.br \\ Mathilde Aparecida Bertoldo \\ Universidade do Vale do Paraíba-UNIVAP, Brasil \\ ma_ra_ga@yahoo.com.br \\ Marlon Ferreira da Silva \\ Universidade do Vale do Paraíba-UNIVAP, Brasil \\ fsilva marlon@yahoo.com.br
}

\section{RESUMO}

Apresentam-se os resultados de correlação entre eventos de deslizamentos e respetivos índices pluviométricos no município de São José dos Campos, com o intuito de estabelecer limiares críticos de chuva para serem utilizados em planos preventivos de defesa civil. Com base nos resultados obtidos sugere-se a adoção de limiares críticos de chuva mais conservadores para a região estudada.

Palavras-chave: Limiares críticos, precipitação, deslizamentos induzidos, Plano Preventivo de Defesa Civil.

\section{ABSTRACT}

We present the correlation results between landslide events and the related rainfall in São José dos Campos, in order to establish a critical thresholds of rainfall to be used in preventive plans of civil defense. Based on the obtained results it is suggested the adoption a more conservative critical rainfall thresholds for the studied.

Keywords: Critical thresholds, rainfall, induced landslides, Preventive Plan of Civil Defense.

\section{RESUMEN}

Estudio de los niveles críticos de lluvia que desencadena deslizamientos en el municipio de São José dos Campos/SP (Brasil) - Presentamos los resultados de la correlación entre los eventos de deslizamientos y respectiva precipitación en São José dos Campos, a fin de establecer umbrales críticos de lluvia para su uso en los planes de prevención de la defensa civil. Basándose en los resultados obtenidos para la región estudiada, se sugiere la adopción de niveles críticos de lluvia más conservadores.

Palabras clave: Niveles críticos, lluvia, deslizamientos inducidos, Plan Preventivo de Defensa Civil.

\section{RÉSUMÉ}

Étude des niveau de précipitation critique qui initie les glissements de terrain sur la municipalité de São Jose dos Campos/SP (Brésil) - Nous présentons les résultats de la corrélation entre les événements de glissements de terrain et leurs précipitations à São José dos Campos, afin d'établir des niveaux critiques de pluie pour une utilisation dans les plans de prévention de la défense civile. Sur la base des résultats obtenus suggèrent l'adoption de niveaux critiques de pluie plus conservatrice pour la région étudiée.

Mots-clé: Niveaux critique, précipitation, induit des glissements de terrain, Plan de Prévention de la Défense Civile.

* O texto deste artigo foi submetido em 02-03-2015, sujeito a revisão por pares a 30-04-2015 e aceite para publicação em 29-07-2015. Este artigo é parte integrante da Revista Territorium, n. ${ }^{\circ} 22,2015,{ }^{\circ}$ RIscos, ISSN: 0872-8941. 
Introdução

No Estado de São Paulo, as atividades de identificação, avaliação e gerenciamento de áreas de riscos geológicos, tiveram início de forma mais sistemática a partir da iniciativa do governo do Estado face aos acidentes em larga escala e com graves consequências que ocorreram no verão de 1987-1988, na região da Serra do Mar. Em função da gravidade dessas ocorrências iniciou-se no ano de 1988, o Plano Preventivo de Defesa Civil - PPDC, elaborado especificamente para escorregamentos nas encostas da Serra do Mar, no Estado de São Paulo (Brasil).

O PPDC constitui um importante instrumento de gestão das áreas de risco a escorregamentos de caráter preventivo que visa à preservação de vidas humanas em diversos municípios do Estado de São Paulo. A principal ação prevista no PPDC é a remoção preventiva das populações que ocupam áreas de risco, antes que os escorregamentos atinjam suas moradias (Macedo et al., 2002 e 2006).

A operacionalidade geral do PPDC envolve ações de monitoramento dos índices pluviométricos (principalmente, chuva acumulada de 72 horas), previsão meteorológica, vistorias de campo e atendimentos emergenciais. Atualmente tais ações são desenvolvidas em 10 (dez) regiões do Estado de São Paulo (Região da Baixada Santista, Região do Litoral Norte; Região do Vale do Paraíba e Serra da Mantiqueira; Região de Sorocaba; Região de Campinas; Aglomeração Urbana de Jundiaí; Região da Capital; Região do ABCD; Região de Guarulhos e Região de Osasco), totalizando o monitoramento de 129 municípios (fig. 1).

A operação do PPDC corresponde a ações preventivas de convivência com os riscos associados a escorregamentos, presentes em regiões constituídas por encostas e taludes inapropriados à ocupação. Geralmente trata-se de áreas ocupadas de forma irregular e sem controle técnico ou planejamento urbano. Assim, o PPDC pode ser considerado um eficiente instrumento de gerenciamento de risco geológico e desastres naturais, estando em concordância com os métodos e técnicas adotadas pelas organizações internacionais de Defesa Civil e recomendado pela ONU (Macedo et al., 1999).

Assim, no presente trabalho buscou-se correlacionar os eventos de deslizamentos ocorridos em diversas áreas de risco situadas no município de São José dos Campos/ SP (Brasil), durante o período de 2009 a 2013, com os respectivos dados de precipitação diária $(\mathrm{mm} / 24 \mathrm{~h})$ e



Fig. 1 - Regiões monitoradas no âmbito do Plano Preventivo de Defesa Civil - PPDC, no Estado de São Paulo-Brasil. (Fonte: modificado de Cedec, 2012).

Fig. 1 - Regions monitored in Preventive Plan of Civil Defense - PPDC, in São Paulo State-Brazil (Source: modified of Cedec, 2012). 
precipitação acumulada de 03 dias $(\mathrm{mm} / 72 \mathrm{~h})$, visando estabelecer limiares críticos de chuva para serem utilizados pela defesa civil de São José dos Campos/SP durante a operação do PPDC.

\section{Área de estudo}

\section{Localização}

O município de São José dos Campos está localizado na região do Vale do Paraíba, na porção leste do Estado de São Paulo (Brasil). É o principal município da região metropolitana do Vale do Paraíba e o mais importante polo aeronáutico e aeroespacial da América Latina. Possui uma área total de $1.099,6 \mathrm{~km}^{2}$, dos quais 353,9 $\mathrm{km}^{2}$ correspondem à área urbana e $745,7 \mathrm{~km}^{2}$ de área rural (PMSJC, 2006). As coordenadas $23^{\circ} 30^{\prime}$ de Latitude Sul, e $45^{\circ} 45^{\prime}$ de Longitude Oeste, correspondem à localização geográfica da área central urbana (fig. 2).

Na região norte do município de São José dos Campos, que representa $70 \%$ da área total, prevalecem compartimentos morfológicos formados por montanhas, serras e picos, e na região sul ( $30 \%$ do território), o relevo é formado predominantemente por planaltos e platôs entrecortados de pequenos vales (PMSJC, 2006). A região norte de São José dos Campos possui cerca de $10 \%$ da população total do município, sendo a região com maior ocorrência de áreas de risco a escorregamentos de todo o município.

Áreas de risco

As áreas de risco de maior susceptibilidade a escorregamentos ocorrem predominantemente na região norte do município de São José dos Campos, sendo
15 (quinze) áreas de risco situadas na região norte e 01 (uma) área de risco localizada na região leste do município (Valério Filho et al., 2014). As 16 áreas de risco ocorrem em diferentes bairros (TABELA I e fig. 3).

TABELA I - Ocorrência das áreas de risco a escorregamentos nos bairros de São José dos Campos.

TABLE I - Occurrence of the landslides risk areas in the districts of São José dos Campos.

\begin{tabular}{|c|c|}
\hline $\begin{array}{c}\text { ÁREA DE RISCO } \\
\text { DE MAIOR } \\
\text { SUSCEPTIBILIDADE }\end{array}$ & DENOMINAÇÃO DO BAIRRO \\
\hline 1 & Dona Nega/Morro dos Macacos \\
\hline 2 & Dona Linda/Freitas \\
\hline 3 & Jardim Guimarães \\
\hline 4 & Chácaras Havaí \\
\hline 5 & Chácara Araújo \\
\hline 6 & Águas de Canindú I e II \\
\hline 7 & Santo Ângelo \\
\hline 8 & Buquirinha I \\
\hline 9 & Buquirinha II \\
\hline 10 & Chácara Oliveira \\
\hline 11 & Mirante do Buquirinha \\
\hline 12 & Altos do Caetê \\
\hline 13 & Chácara Taquari \\
\hline 14 & Chácara dos Florindos \\
\hline 15 & Chácaras Miranda \\
\hline 16 & Fazenda Boa Vista \\
\hline
\end{tabular}

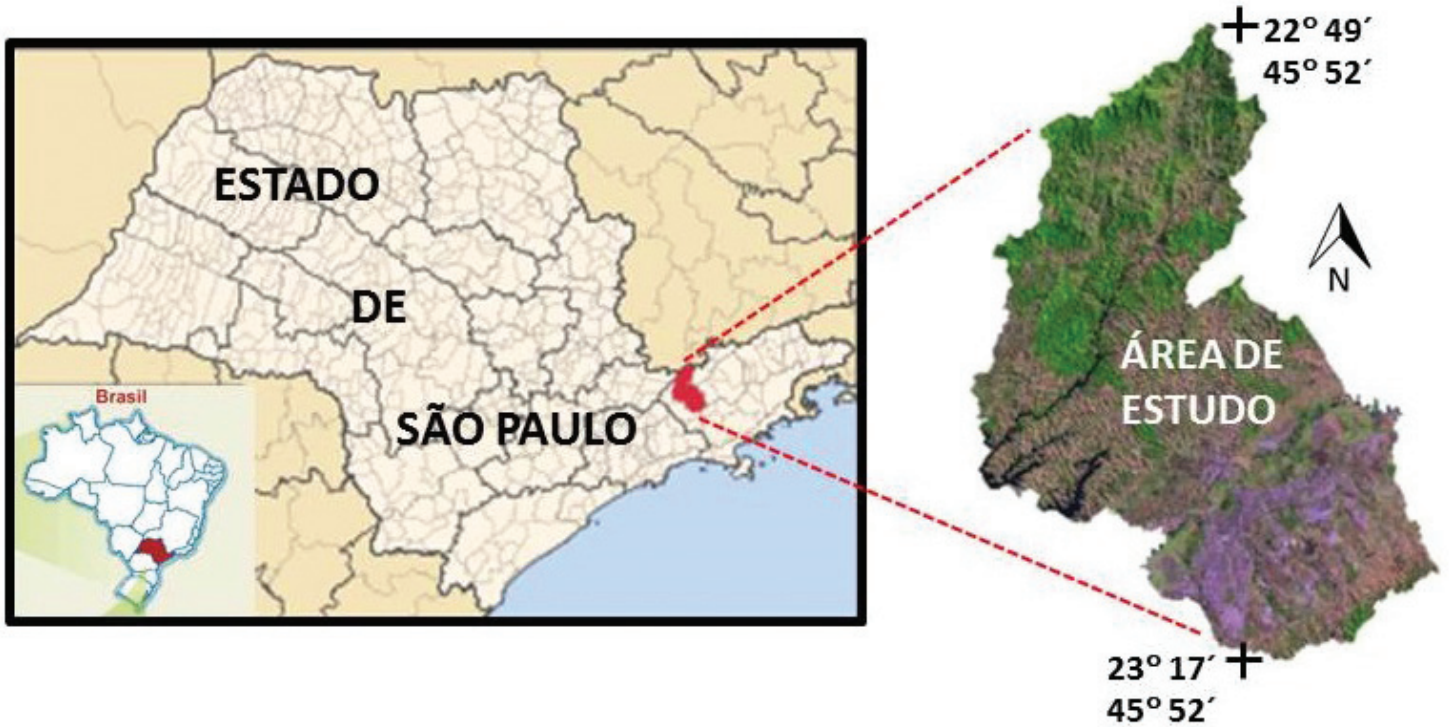

Fig. 2 - Localização da área de estudo (Fonte: modificado de VirtualeducaBrasil, 2015).

Fig. 2 - Localization of the studied area (Source: modified of VirtualeducaBrasil, 2015). 


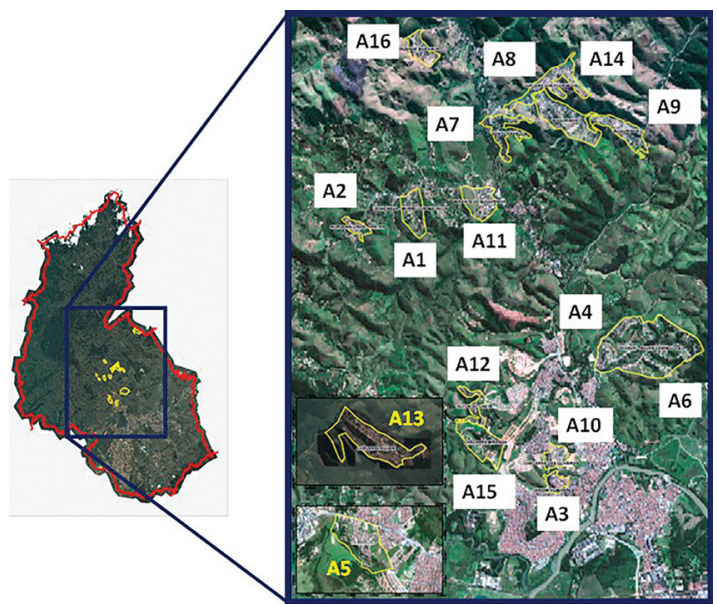

Fig. 3 - Localização das áreas de risco a escorregamento no município de São José dos Campos. (Fonte: Valério Filho et al., 2014).

Fig. 3 - Localization of the landslides risk area in municipality of São José dos Campos (Source: Valério Filho et al., 2014).

Nas 16 áreas de risco ocorrem predominantemente escorregamentos do tipo planar raso induzido, geralmente associados às intervenções antrópicas, principalmente por meio da execução de taludes de corte e aterro. Assim, as feições de instabilidade (trincas nas moradias, trincas nos terrenos, degraus de abatimento, muros ou paredes "embarrigados") também se devem ao direcionamento inadequado das águas servidas e pluviais por causa da ausência de infraestrutura urbana; ao desmatamento com plantio de roças; à instalação de fossas negras; à disposição de lixo e entulho (Valério Filho et al., 2014).

As áreas de risco no município de São José dos Campos caracterizam-se pela existência de vários núcleos habitacionais de expansão, distribuídos de maneira descontínua ao norte da mancha urbana original (15 bairros) e construídos em terrenos altamente suscetíveis à ocorrência de processos de escorregamentos. Os condicionantes naturais de tais terrenos são caracterizados por declividades elevadas (acima de $25^{\circ}$ ), principalmente nas porções de meia encosta e topo (Valério Filho et al., 2014).

Quanto ao padrão de ocupação, as áreas de risco apresentam, predominantemente, setores caracterizados por média densidade de ocupação com casas de alvenaria de um ou dois pavimentos de médio padrão construtivo, sendo que algumas áreas de risco ainda estão em estágio de ocupação dispersa, mas que merecem ações de congelamento imediato para evitar novas construções. Uma análise complementar permite verificar uma correlação entre as características específicas do uso e ocupação do solo e os graus de risco diferenciados. Essa conspícua correlação é decorrente, primeiramente, das características de implantação dos assentamentos urbanos devido aos fatores indutores dos escorregamentos (cortes, aterros, ausência de infraestrutura urbana, lançamento de água servida, etc.) e, secundariamente, devida às características regionais do meio físico (geológicas, geotécnicas e geomorfológicas), principalmente na porção norte do município, onde predominam regiões com alta suscetibilidade natural a escorregamentos (Valério Filho et al., 2014).

\section{Características regionais do meio físico}

Na região do Vale do Paraíba, onde está situada a área de estudo, o clima é tropical úmido, com variações pluviométricas decorrentes das mudanças de relevo. Os altos serranos da Mantiqueira (ao norte) e a borda da Serra do Mar (ao sul) são os dois setores em que a pluviosidade é maior, atingindo facilmente valores de $1.700 \mathrm{~mm}$ anuais. Estas serranias influenciam orograficamente a gênese das chuvas na região do Vale do Paraíba, as quais variam anualmente entre 1.200 $\mathrm{mm}$, na região de planície, a $1.900 \mathrm{~mm}$ na Serra da Mantiqueira (IPT, 1981 e 1990).

No município de São José dos Campos os solos são classificados regionalmente em cinco tipos, sendo sua ocorrência diretamente relacionada com os nivelamentos topográficos da região. Assim, nas áreas de mais altas declividades ocorrem solos pouco evoluídos originados das rochas cristalinas (granitos/gnaisses/ xistos), enquanto nas áreas de relevos planos ocorrem solos bastante evoluídos (Oliveira, 1999). No município ocorrem predominantemente Latossolos (LVA) e Argissolos (PVA) na região norte, onde se encontram 15 áreas de risco a escorregamentos de maior susceptibilidade, e Gleissolos (GM) e Argissolos (PVA) na região sul.

Os Latossolos (LVA), originários de granitos e gnaisses, ocorrem em regiões de paleovale do rio Paraíba do Sul e baixas vertentes da Serra da Mantiqueira, em relevos suavemente ondulados a ondulados, com altimetria variando de 800 a 1.000 metros. Os Argissolos (PVA), de origem granito-gnáissica e xisto, ocorrem em regiões de zonas pré-montanhosas, em relevos ondulados a fortemente ondulados, com altimetria entre 1.000 a 1.200 metros (Oliveira, 1999).

Com relação à litologia, na área estudada ocorrem regionalmente rochas cristalinas (ígneas e metamórficas) dos complexos: (i) Amparo, (ii) Embu, (iii) Paraíba do Sul e (iv) Paraisópolis. Ocorrem também rochas sedimentares da formação Taubaté (Terciário Superior) e depósitos quaternários (aluviões). Nos complexos citados, predominam gnaisses e suítes graníticas. Nas rochas cristalinas, a geomorfologia no município está caracterizada por Morros Alongados/Arredondados e Serras Médias, Altas e Escarpadas, onde está situada a maior parte das áreas de risco mais elevado a 
escorregamentos. Os planaltos e escarpas são sustentados por rochas mais resistentes, enquanto lineamentos rochosos e a rede de drenagem são condicionados por falhas, fraturas e zonas de cisalhamento. Em terrenos sedimentares, ocorrem planícies aluviais, terraços e colinas terciárias (Camargo et al., 2011).

\section{Metodologia}

Limiares críticos de chuva utilizados na operação do PPDC

A concepção operacional do PPDC baseia-se na possibilidade de serem tomadas medidas preventivas antes da deflagração dos deslizamentos (remoção dos moradores das áreas de risco), a partir da previsão das condições potencialmente favoráveis à sua ocorrência, ou seja, por meio do monitoramento diário da previsão meteorológica e da precipitação acumulada de 72 horas. Resumidamente, a ação de remoção preventiva fundamenta-se nas análises das vistorias de campo para a identificação de indícios de movimentação dos terrenos (trincas, degraus de abatimento, cicatrizes de escorregamentos, etc.), que são realizadas nas áreas de risco somente quando os valores de precipitação acumulada de 72 horas forem iguais ou maiores que os limiares críticos estabelecidos no PPDC.

A definição desses limiares críticos leva em consideração que a água da chuva é o principal agente preparatório e deflagrador dos deslizamentos (Pichler, 1957, Barata, 1969 e Nunes, 1969). Nielsen e Turner (1975) afirmam que existe um limiar crítico de chuva para cada região, acima do qual serão desencadeados os deslizamentos em taludes e encostas. Deste modo, a questão principal a ser respondida é: qual a quantidade de água de chuva necessária para a deflagração dos deslizamentos? Buscando respondê-la diversos pesquisadores realizaram análises de correlação entre chuvas e deslizamentos, com o intuito de relacionar os eventos de deslizamento com os dados de chuvas.

Por exemplo, Au (1998) estudou diversos eventos de deslizamentos de taludes deflagrados pela chuva em Hong Kong. Segundo o autor, a chuva acumulada tem pouca influência nas rupturas, sendo estas mais influenciadas pelas chuvas intensas de curta duração. Quinta Ferreira et al. (2005) analisaram a influência da precipitação na ocorrência de deslizamentos para a cidade de Coimbra, no período de 1864 a 2003. Os resultados encontrados indicam que os escorregamentos não estão diretamente relacionados à precipitação acumulada ao longo do ano, e sim aos picos de intensidade pluviométrica.

No Brasil, Guidicini e Iwasa (1976) analisaram os índices pluviométricos e respectivas ocorrências de deslizamentos na Serra do Mar e Serra da Mantiqueira.
Tais autores concluíram que: $1^{\circ}$ ) precipitações em eventos contínuos acima de 250-300 mm há ocorrência sistemática de deslizamentos; $2^{\circ}$ ) precipitações acima de $20 \%$ da média anual tendem a deflagrar deslizamentos catastróficos e $3^{\circ}$ ) precipitações acima de $12 \%$ da média anual tendem a saturar o substrato até um grau crítico, podendo a partir daí, deflagrar deslizamentos, independentes do valor acumulado de chuva anterior.

No Estado de São Paulo, um dos estudos pioneiros é a correlação elaborada por Tatizana et al. (1987a e 1987b) para a região de Cubatão (Serra do Mar), que se baseia na análise de dados de deslizamentos e chuva acumulada de 4 dias e precipitação diária, para um período de mais de 30 anos. Os resultados de correlação obtidos por esses autores foram posteriormente extrapolados para toda a região da Serra do Mar e para outras regiões do Estado de São Paulo, tendo como referência os dados de precipitação acumulada para um período de 3 dias $(\mathrm{mm} / 72 \mathrm{~h})$. Deste modo, se estabeleceram, para os 129 municípios atualmente monitorados pelo PPDC, os seguintes limiares críticos de precipitação (mm/72 horas): Região de Campinas - 80; Região da Baixada Santista - 100; Região do Litoral Norte - 120; Região de Sorocaba - 80; Região do ABCD - 100; Região do Vale do Paraíba - 100 e Serra da Mantiqueira - 80 .

Neste contexto, verifica-se que tais limiares críticos de chuva vêm sendo adotados no PPDC desde o verão de 1988-1989, no Estado de São Paulo (Brasil). Recentemente, Santoro et al. (2010) analisaram dados de chuva e deslizamentos ocorridos durante a operação do PPDC, para o período de 2000 a 2010, com o intuito de avaliar a aplicabilidade desses limiares críticos de chuva estabelecidos para os municípios do Estado de São Paulo. Os autores concluíram que se devem adotar limiares críticos de chuva mais conservadores para a operação do PPDC, visando à antecipação das ações de vistorias de campo. Para isso, recomendaram a mudança da faixa de valores de limiares críticos de precipitação, de 80 a 120 $\mathrm{mm} / 72 \mathrm{~h}$, para 60 a $100 \mathrm{~mm} / 72 \mathrm{~h}$, conforme as diferentes regiões operadas pelo PPDC (fig. 4).

Observa-se a incidência de alguns deslizamentos na zona "B", região onde teoricamente não se espera a ocorrência de deslizamentos, inclusive com valores menores de limiares críticos de precipitação para a deflagração de tais deslizamentos (fig. 4). Essas discrepâncias se devem principalmente ao fato da não consideração dos condicionantes climáticos e geotécnicos, bem como dos fatores indutores antrópicos peculiares de cada município onde os deslizamentos ocorreram. Ou seja, os limiares críticos de precipitação devem ser estabelecidos, preferencialmente, de maneira discretizada, conforme as características naturais e antrópicas de cada região (Santoro et al., 2010). 


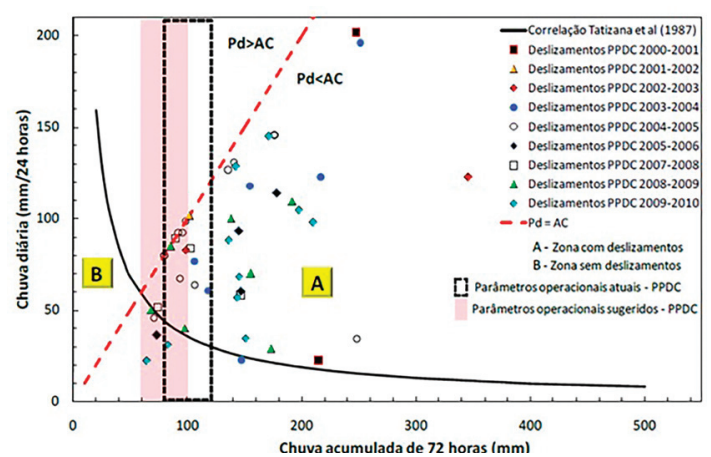

Fig. 4 - Gráfico com parâmetros operacionais sugeridos para o PPDC e correlação proposta por Tatizana e colaboradores (Fonte: Santoro et al., 2010).

Fig. 4 - Graphic with operational parameters suggested for the PPDC and correlation curve proposal by Tatizana and collaborators (Source: Santoro et al., 2010).

Desta forma, no presente trabalho buscou-se estabelecer os limiares críticos de chuva, a partir das análises de correlação de chuva e deslizamentos, levando-se em consideração as particularidades climáticas (distribuição espacial da precipitação) e dos fatores indutores antrópicos (lançamento de água servida, cortes, aterros, fossas, etc.) das áreas de risco do município de São José dos Campos.

\section{Análise dos dados para correlação}

Inicialmente foram obtidas as ocorrências de deslizamentos cadastradas pela Defesa Civil de São José dos Campos, durante a operação do PPDC no período de 2009 a 2013. Posteriormente foram selecionadas as ocorrências associadas predominantemente com processos induzidos de deslizamentos em taludes de corte/aterro e, secundariamente, as ocorrências de deslizamentos em encostas naturais deflagrados por algum fator antrópico (e.g. lançamento de água servida, fossa negra). Deste modo, não foram considerados os registros envolvendo processos associados à queda/ rolamento/desplacamento de blocos rochosos, rastejo e corridas de detritos.

Portanto, os dados inicialmente obtidos neste trabalho correspondem a 106 ocorrências de deslizamentos induzidos cadastrados durante a operação do PPDC pela defesa civil de São José dos Campos, no período de 2009 a 2013 (TABELA II). Desse total inicial foram selecionadas 58 ocorrências de deslizamentos em quatro (04) bairros para o estudo de correlação com os dados de precipitação (dados destacados em vermelho na TABELA II e pontos vermelhos na fig. 5).

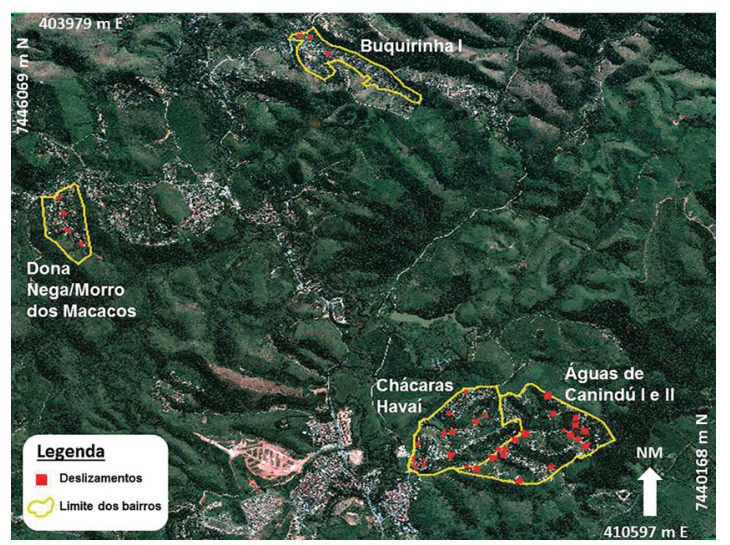

Fig. 5 - Distribuição dos 58 escorregamentos registrados pela defesa civil de São José dos Campos durante a operação do PPDC, no período de 2009 a 2013.

Fig. 5 - Distribution of the 58 landslides recorded by civil defense of São José dos Campos during the operation of the PPDC, in period of 2009 to 2013.

TABELA II - Ocorrências registradas pela defesa civil de São José dos Campos durante a operação do PPDC no período de 2009 a 2013.

Os dados destacados em vermelho representam as 58 ocorrências de deslizamentos selecionadas para o estudo de correlação.

TABLE II - Occurrences recorded by civil defense of São José dos Campos during the operation of the PPDC in period of 2009 to 2013. The data featured in red represent the 58 occurrences of landslides selected for the correlation study.

\begin{tabular}{|c|c|c|c|c|c|c|c|}
\hline \multirow{2}{*}{ Região } & \multirow{2}{*}{ Bairro } & \multicolumn{5}{|c|}{$N^{\circ}$ de Ocorrências de Deslizamentos } & \multirow{2}{*}{$\begin{array}{c}\text { Total de Deslizamentos/ } \\
\text { Bairro }\end{array}$} \\
\hline & & 2009 & 2010 & 2011 & 2012 & 2013 & \\
\hline \multirow{13}{*}{ Norte } & Chácara Oliveira & 01 & - & 02 & - & - & 03 \\
\hline & Jardim Guimarães & - & 01 & - & 02 & 01 & 04 \\
\hline & Dona Nega/Morro dos Macacos & 02 & - & 02 & - & 01 & 05 \\
\hline & Mirante do Buquirinha & 02 & 09 & 01 & - & - & 12 \\
\hline & Águas de Canindú I e II & 09 & 07 & 11 & 04 & 04 & 35 \\
\hline & Chácaras Havaí & 01 & 02 & 08 & 03 & - & 14 \\
\hline & Chácaras Miranda & - & 02 & 01 & 01 & - & 04 \\
\hline & Altos do Caetê & - & 02 & - & - & - & 02 \\
\hline & Buquirinha I & 02 & 01 & 01 & - & - & 04 \\
\hline & Buquirinha II & 01 & 01 & 01 & - & 01 & 04 \\
\hline & Fazenda Boa Vista & - & 02 & - & - & 02 & 04 \\
\hline & Chácara Taquari & 09 & 03 & 03 & - & - & 15 \\
\hline & Total Geral de Deslizamentos & 27 & 30 & 30 & 10 & 09 & 106 \\
\hline
\end{tabular}


Os dados de precipitação utilizados para as análises de correlação foram obtidos de duas Plataformas de Coleta de Dados (PCDs), sendo uma instalada no campus da Universidade do Vale do Paraíba-UNIVAPe a outra instalada no Instituto Nacional de Pesquisas Espaciais-INPE; ambas situadas na região de planície do Vale do Paraíba. Por ser a precipitação um dos principais fatores preparatórios e deflagradores dos deslizamentos, o conhecimento detalhado do seu comportamento e distribuição torna-se imprescindível nas análises de correlação. Desta forma, buscou-se, preliminarmente, avaliar as características de variabilidade espaço-temporal da precipitação na região do Vale do Paraíba, a partir dos estudos realizados por Nery et al. (1999) e Perrella e Ferreira (2002), para posteriormente avaliar a representatividade espacial dos dados de precipitação das PCDs da UNIVAP e do INPE em relação aos dados de deslizamentos.

A avaliação da distribuição da precipitação anual média no município estudado baseou-se nas informações contida no mapa de isoietas obtido por Perrella e Ferreira (2002), a partir da utilização de dados de precipitação de 111 postos pluviométricos do DAEE, para um período de 30 anos - 1966 a 1997 (fig. 6). Nota-se que as precipitações máximas são encontradas nas regiões da Serra do Mar e Serra da Mantiqueira (2.200 e 1.900 mm, respectivamente - fig. 6). No Vale do Paraíba, onde está situado o município de São José dos Campos, existem gradientes de distribuição de precipitação significativos (fig. 6). Na região sul da área estudada as precipitações máximas anuais é da ordem de $1.300 \mathrm{~mm}$, enquanto que na direção norte do município os valores aumentam significativamente, chegando ao valor máximo de 1.900 $\mathrm{mm}$ na Serra da Mantiqueira (fig. 6).

A distribuição espacial destes gradientes também pode ser comprovada por meio da análise dos dados de chuva de cinco postos pluviométricos do DAEE instalados no município de São José dos Campos: Posto A - São José dos Campos; Posto B - Água Soca; Posto C - Represa; Posto D - Guirra e Posto E - São Francisco Xavier (fig. 7). Observa-se (fig. 7), que os postos pluviométricos situados no extremo norte do município (E e D) apresentam uma precipitação média anual mais elevada (da ordem de $1.800 \mathrm{~mm}$ ) do que os demais postos pluviométricos ( $\mathrm{A}, \mathrm{B}$ e $\mathrm{C}$ ). Logo, constata-se a considerável variação espacial da precipitação média anual no município de São José dos Campos. Esta constatação evidencia a importância de se considerar, nos estudos de correlação entre chuva e deslizamentos, as variabilidades espaciais de precipitação.

\section{Resultados}

Os dados referentes aos 58 deslizamentos registrados pela defesa civil de São José dos Campos, durante a operação do PPDC, associados com processos de escorregamentos

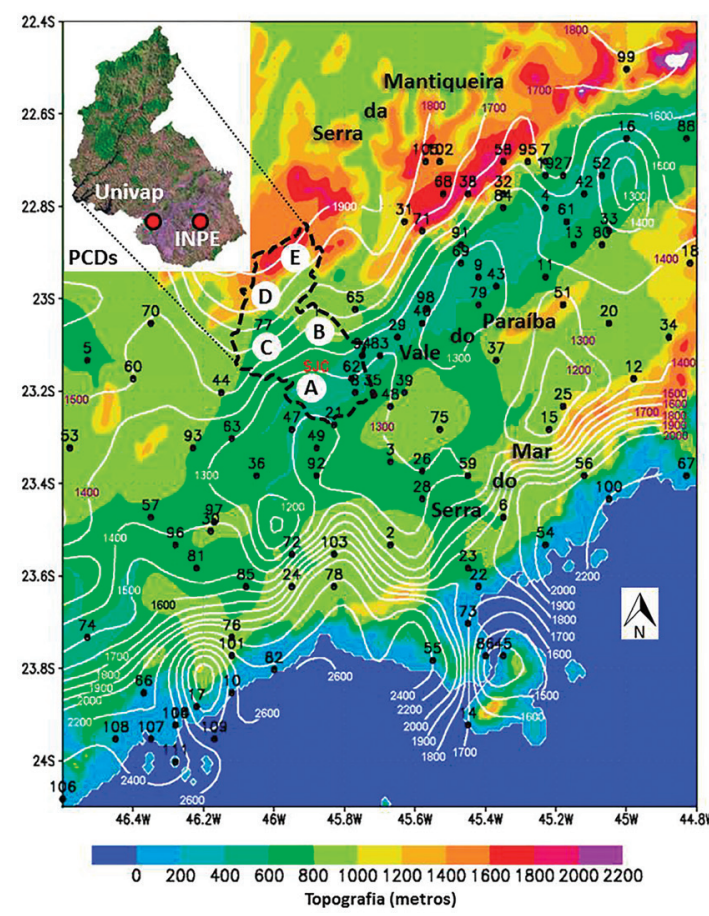

Fig. 6 - Distribuição da precipitação - mapa de isoietas - para a Serra do Mar, Vale do Paraíba e Serra da Mantiqueira; localização dos pluviômetros da UNIVAP e do INPE - pontos vermelhos; localização dos postos pluviométricos do DAEE - pontos brancos na área estudada (A, B, C, D e E) e pontos pretos nas demais regiões. (Fonte: modificado de Perrella e Ferreira, 2002).

Fig. 6 - Distribution of the precipitation - isovalues map - for the Serra do Mar, Vale do Paraiba e Serra da Mantiqueira; localization of the rain gauges of the UNIVAP and INPE - red points; localization of the rain gauges stations of the DAEE white points in studied area $(A, B, C, D$ and $E)$ and black points in others areas (Source: modified of Perrella e Ferreira, 2002).

em encostas e taludes de corte/aterro, para o período de 2009 a 2013, foram analisados a partir de gráficos de chuva diária $(\mathrm{mm} / 24 \mathrm{~h})$ versus chuva acumulada de 03 dias (fig. 8). No gráfico da fig. 8 encontram-se indicados pelas setas vermelha e preta, respectivamente, o limiar crítico de chuva sugerido por Santoro et al. (2010) e o limiar crítico de chuva adotado no PPDC para o município de São José dos Campos, e ainda a curva de correlação de Tatizana et al. (1987a e 1987b).

Analisando a distribuição dos dados de correlação (fig. 8), observa-se que um número considerável de deslizamentos está situado abaixo da curva de correlação de Tatizana, ou seja, estão situados na zona de não ocorrência de deslizamentos. Além disso, os dados de ambas as plataformas de coleta de dados (INPE e UNIVAP) apresentam valores de precipitação acumulada de 03 dias significativamente menores, quando comparados com o limiar crítico de chuva atualmente adotado para o município de São José dos Campos no PPDC (100 $\mathrm{mm} / 72 \mathrm{~h}$ - seta preta) e com aquele sugerido por Santoro e colaboradores $(80 \mathrm{~mm} / 72 \mathrm{~h}$ - seta vermelha). 

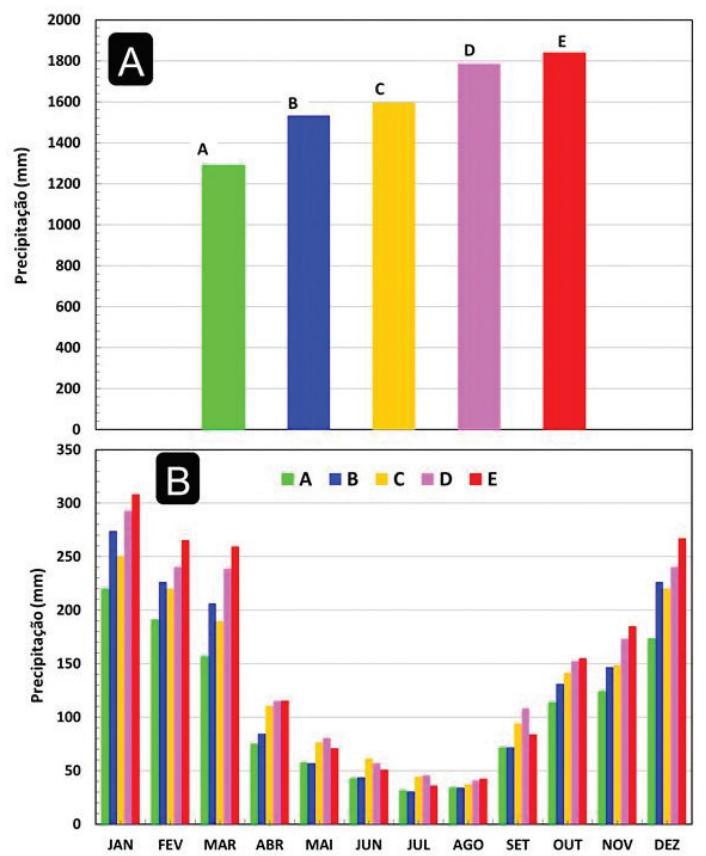

Fig. 7 - Gráficos de precipitação média anual (A) e mensal (B) dos cinco postos pluviométricos do DAEE situados no município de São José dos Campos (A, B, C, D e E).

Fig. 7 - Graphics of average annual (A) and monthly (B) rainfall of five rain gauge stations of the DAEE localized in municipality of São Jose dos Campos (A, B, C, D and E).

Verifica-se, também, que alguns pontos de deslizamentos estão situados próximos da linha "precipitação diária $(\mathrm{Pd})=$ precipitação acumulada $(\mathrm{Pacm})$ ", sugerindo que a chuva diária desempenhou uma influência mais significativa para a deflagração dos deslizamentos do que a chuva acumulada. Alguns deslizamentos estão situados sobre a linha “Pd=Pacm", ou seja, os deslizamentos provavelmente foram deflagrados para a condição de chuva acumulada igual à chuva diária. Nestes casos, provavelmente a intensidade de chuva horária ao longo do dia desempenhou um papel mais importante na deflagração de tais eventos.

No entanto, observa-se (fig. 8), que muitos deslizamentos foram deflagrados para condições de precipitação (diária e/ou acumulada) consideravelmente abaixo dos limiares críticos de chuva usualmente adotados no PPDC, ou mesmo daqueles sugeridos na literatura nacional (Tatizana et al., 1987a e 1987b, Elbachá et al., 1992 e Almeida et al., 1993). Mas, por exemplo, a ocorrência de deslizamentos induzidos no município de Belo Horizonte (< 6 eventos) está associada com chuvas acumuladas entre 10 a $50 \mathrm{~mm}$, geralmente devido à indução dos condicionantes antrópicos, tais como vazamentos e ruptura de tubulações, muitas vezes mais importantes ao desencadeamento do processo do que a própria chuva (Parizzi et al., 2010).

Pode-se sugerir a adoção de limiares críticos de chuva conservadores para a deflagração de deslizamentos

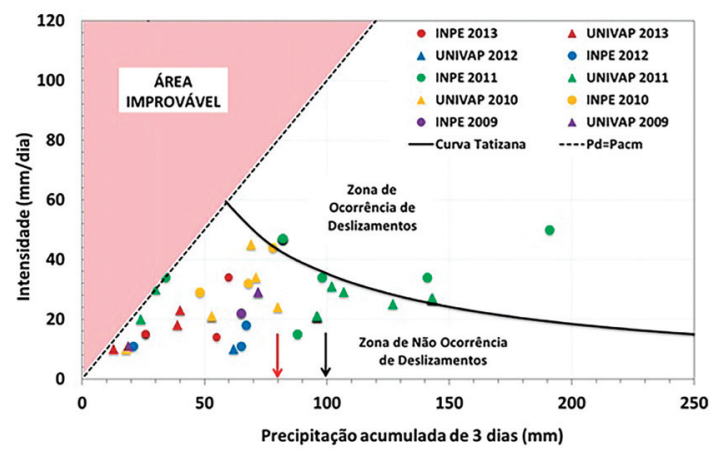

Fig. 8 - Gráfico com os dados de chuva diária versus chuva acumulada de 72 horas obtidos das PCDs da UNIVAP e do INPE, e respectivos pontos de deslizamentos ocorridos no âmbito do PPDC, para o período de 2009 a 2013.

Fig. 8 - Graphic with the data of rain daily versus rain accumulated of 72 hours obtained of the UNIVAP and INPE station, and respective landslides points that occurred on PPDC, in period of 2009 to 2013.

exclusivamente induzidos no município de São José dos Campos, tomando-se como base limiares de chuva similares àqueles propostos por Parizzi et al. (2010) pois, desta forma, a maioria dos dados de deslizamentos ficam situados acima da curva de correlação sugerida (linha tracejada amarela), ou seja, na zona de ocorrência de deslizamentos (fig. 9).

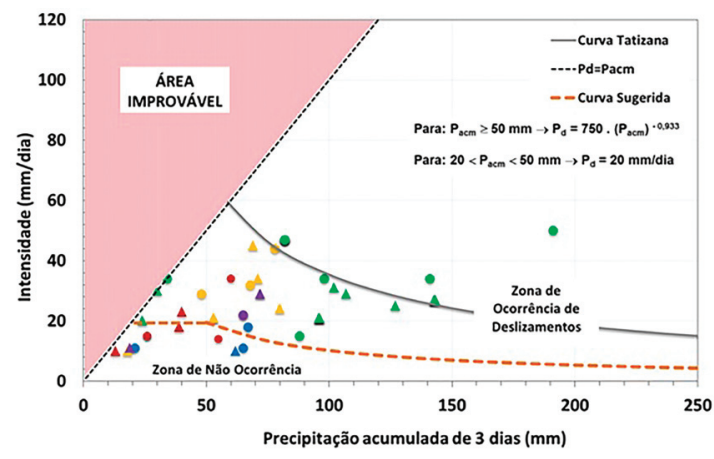

Fig. 9 - Curva de correlação entre chuva e deslizamentos induzidos sugerida (linha tracejada marrom) para o município de São José dos Campos/SP.

Fig. 9 - Correlation curve between rain and induced landslides suggested (dashed yellow brown) for the municipality of São Jose dos Campos/SP.

No entanto, acredita-se que a obtenção de limiares críticos de chuva tão baixos no presente trabalho pode estar relacionada, de certa forma, com duas hipóteses fundamentais: $1^{\text {a }}$ ) o aumento das intervenções antrópicas nas áreas de risco, por meio do aumento da quantidade de taludes de corte e aterro, lançamento de água servida, fossas negras, concentração de águas de chuvas, etc.; $2^{a}$ ) a representatividade dos dados de chuva utilizados na correlação (PCDs da UNIVAP e do INPE) em relação à distribuição espaço-temporal dos deslizamentos e das variações espaciais e dos gradientes pluviométricos observados no município de São José dos Campos. 
a) Análise da $1^{\text {a }}$ hipótese - diminuição dos limiares críticos de chuva devido ao aumento dos fatores indutores de deslizamentos - buscou-se constatar essa hipótese por meio da análise da variação do adensamento urbano na principal área de risco (definida como sendo aquela onde ocorreu o maior número de deslizamentos, ou seja, no bairro Águas de Canindú I e II), utilizando-se imagens de satélite de alta resolução obtidas nos anos de 2007, 2010 e 2012. Ao analisar os mapas de evolução da densidade de ocupação (figuras 10A, $10 B$ e $10 C$ ), nota-se que houve um ligeiro aumento do adensamento urbano apenas na porção central da área de risco, onde inclusive percebe-se a recorrência de alguns deslizamentos nos anos subsequentes (em 2010 e 2012). Apesar da ínfima evolução do adensamento urbano, acredita-se que os baixos valores de limiares críticos obtidos possam estar relacionados, de certa forma, com alguns fatores indutores instalados em moradias pré-existentes (e.g. execução de taludes de corte e aterro para ampliação das moradias), principalmente para aqueles limiares situados abaixo da curva sugerida (fig. 9). No entanto, a metodologia adotada não permite afirmar categoricamente que os fatores indutores possam ter causado a diminuição de todos os limiares críticos de chuva analisados.

b) Análise da $2^{\text {a }}$ hipótese - problema de representatividade espacial dos dados de chuva das PCDs em relação aos gradientes pluviométricos existentes na área estudada - buscou-se constatar a existência de diferenças significativas entre as precipitações registradas pelas PCDs do INPE e da UNIVAP, e as precipitações que possam ter ocorrido nos locais dos deslizamentos, a partir da análise das informações constantes nas figuras 5, 6 e 7. Na fig. 5 nota-se que a totalidade dos escorregamentos ocorreu na região norte do município, onde se encontram dois postos pluviométricos do DAEE (pontos brancos C e B, na fig. 6), entre isoietas de precipitação de 1.500 a $1.600 \mathrm{~mm}$ (fig. 6). As PCDs da UNIVAP e do INPE estão instaladas nas regiões oeste e leste, respectivamente, entre isoietas de precipitação de 1.200 a 1.300 mm (fig. 6), e na mesma região pluviométrica de um dos postos pluviométricos do DAEE (ponto branco $\mathrm{A}$, na fig. 6). Admitindo-se uma distribuição homogênea (isovalores) de precipitação média anual e mensal para as respectivas regiões onde estão situados os postos pluviométricos “A, B e C" do DAEE (fig. 6 e 7), tem-se supostamente que nos locais de ocorrência dos deslizamentos (região norte) os valores acumulados médios de precipitação pode ter sido da ordem de até $300 \mathrm{~mm} / \mathrm{ano}$ e
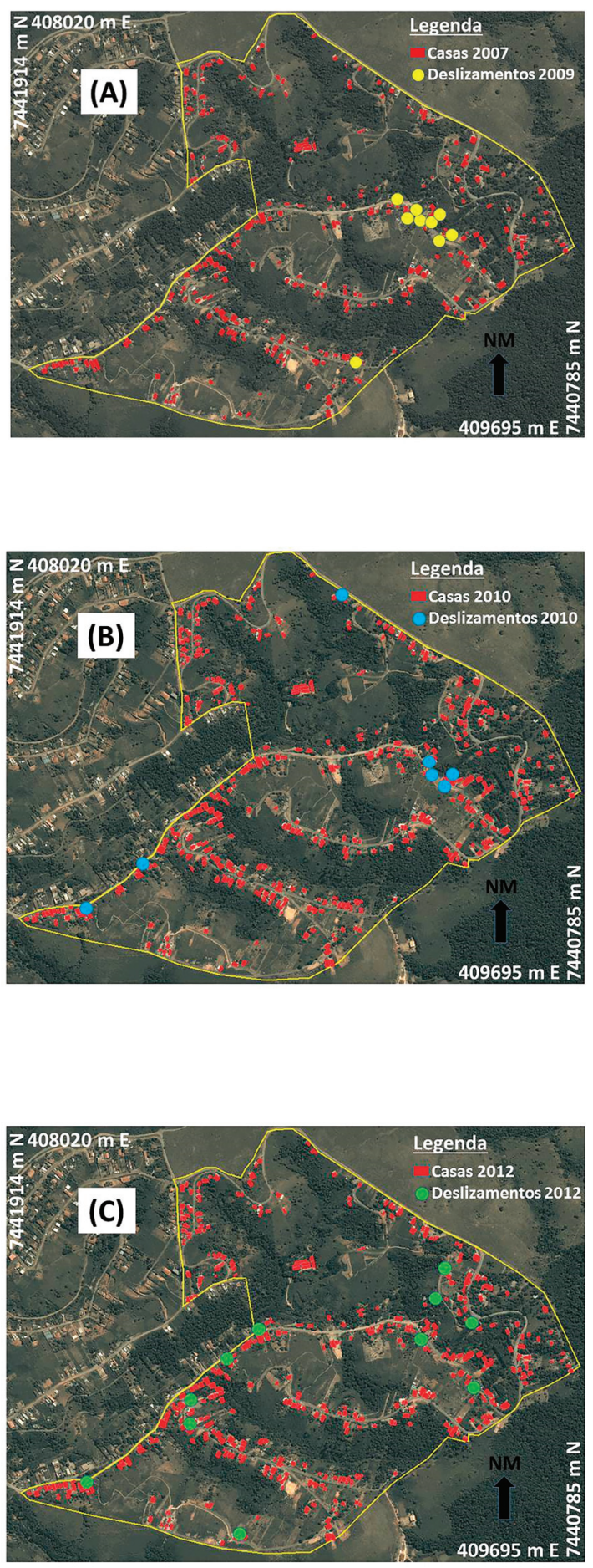

Fig. 10 - Mapas de evolução da densidade de ocupação do bairro Águas de Canindú I e II, durante os anos de 2007, 2010

e 2012 (retângulos em vermelho), e respectivos pontos de deslizamentos ocorrido s no âmbito do PPDC nos anos de 2009 (A), 2010 (B) e 2012 (C).

Fig. 10 - Maps of evolution of the occupation density of the district Aguas de Canindu I and II, for the years of 2007, 2010 and 2012 (red rectangles), and respective landslides points occurred in PPDC in years of 2009 (A), 2010 (B) and 2012 (C), 
$50 \mathrm{~mm} / \mathrm{mês}$ (dezembro a março) maiores do que os valores registrados pelas estações do INPE e UNIVAP (regiões leste e oeste). Nestas condições, espera-se que os dados de precipitação das duas PCDs utilizadas no presente estudo de correlação tendem a subestimar os reais valores de limiar crítico de chuva deflagradores dos deslizamentos ocorridos no município de São Jose dos Campos, para o período considerado.

\section{Conclusão}

Em termos gerais, considerou-se que tanto a chuva diária (valores entre 20 a $50 \mathrm{~mm} / 24 \mathrm{~h}$ ) quanto a precipitação acumulada de 03 dias (valores acima de $50 \mathrm{~mm} / 72 \mathrm{~h}$ ) são fatores fundamentais para a deflagração de escorregamentos induzidos no município estudado.

Os resultados do estudo de correlação apresentaram um número considerável de deslizamentos situados na zona de não ocorrência de deslizamentos, segundo a curva de correlação proposta por Tatizana et al. (1987a e 1987b), com valores de precipitação acumulada (mm/72h) significativamente menores do que aqueles adotados nos planos preventivos de defesa civil e sugeridos pela literatura nacional.

Sugeriu-se, no presente trabalho, a adoção de limiares críticos de chuva mais conservadores para a deflagração de deslizamentos induzidos no município de São José dos Campos, a partir do uso da "curva de correlação" apresentada na fig. 9, dividida em dois trechos definidos pelas seguintes equações: i) para $P_{\text {acm }} \geq 50 \mathrm{~mm}$, usar a equação $P_{d}=750 .\left(P_{a c m}\right)^{-0.933}$; ii) para $20<P_{\text {acm }}<50 \mathrm{~mm}$, adotar a equação $P_{d}=20 \mathrm{~mm} /$ dia, sendo $P_{\text {acm }}$ e $P_{d}$ a precipitação acumulada de 3 dias $(\mathrm{mm} / 72 \mathrm{~h})$ e a precipitação diária $(\mathrm{mm} / 24 \mathrm{~h})$, respectivamente.

Entretanto, recomenda-se a utilização da curva de correlação apenas como uma referência preliminar de limiares críticos de chuva para a deflagração de escorregamentos induzidos pontuais, a ser ainda validada por meio de estudos e análises futuras, pois se supõe que os dados de precipitação utilizados no presente estudo para obtenção da curva de correlação podem estar subestimados devido à existência de notáveis gradientes climatológicos na região estudada, e que não foram ainda considerados na curva de correlação sugerida.

Finalmente, ressalta-se a importância da consideração da variabilidade e dos gradientes espaciais da precipitação em estudos futuros que se propõem a aperfeiçoar os limiares críticos de chuvas aqui sugeridos, tornandoos mais condizentes com a realidade climatológica da região estudada, por exemplo, a partir da instalação de pluviômetros nas áreas de risco da região norte de forma mais discretizada, seguindo-se a distribuição espacial das isoietas de precipitação (fig. 6).

\section{Agradecimentos}

Os autores agradecem à Coordenadoria Municipal de Defesa Civil de São José dos Campos pela cessão dos dados de deslizamentos utilizados no presente trabalho. Agradecem também à UNIVAP e ao INPE pela cessão dos dados pluviométricos utilizados no presente estudo.

\section{Referências bibliográficas}

Almeida, M. C. J., Nakazawa, A., Tatizana, C. (1993). Análise de correlação entre chuvas e escorregamentos no Município de Petrópolis, RJ. Congresso Brasileiro de Geologia de Engenharia e Ambiental, 7, 1993, Poços de Caldas, Anais impressos, p. 129-133.

Au, S. W .C. (1998). Rain-induced slope instability in Hong Kong. Engineering Geology, vol. 51, Canada, p. 01-36.

Barata, F .E. (1969). Landslides in the tropical region of Rio de Janeiro. International Conference on Soil Mechanics and Foundation Engineering, 7, 1969, Mexico, Proceedings, vol. 2, p. 507-516.

Camargo, F. F., Florenzano, T. G., Almeida, C. M., Oliveira, C. G. (2011). Mapeamento geomorfológico com imagens estereoscópicas digitais do sensor ASTER/Terra. Geociências, vol. 30/n. ${ }^{\circ}$ 1, São Paulo, p. 95-104.

CEDEC-COORDENADORIA ESTADUAL DE DEFESA CIVIL (2012). Desastres naturais e riscos geológicos no Estado de São Paulo: cenário de referência-2012. Boletim $n^{\circ} 1$ do GAAE, São Paulo, 97p. Disponível em http://www.defesacivil.sp.gov. br/v2010/portal_defesacivil/conteudo/ documentos/pdn/boletimgaae27dez2012.pdf. [Acessado em 21/10/2014].

Elbachá, A. T., Campos, L. E. P., Bahia, R. F. C. (1992). Tentativa de correlação entre precipitação e deslizamentos na cidade de Salvador. Conferência Brasileira sobre Estabilidade de Encostas, 15t 1992 , Rio de Janeiro, Anais impressos, p. 647-673.

Guidicinl, G., Iwasa, O. Y. (1976). Ensaio de correlação entre pluviosidade e escorregamentos em meio tropical úmido. São Paulo, Publicação IPT $\mathrm{n}^{\circ}$ 1080, 48p.

IPT-INSTITUTO DE PESQUISAS TECNOLÓGICAS DO ESTADO DE SÃO PAULO (1990). Geologia das folhas Jacareí (SF. 23-Y-D-II-3), Tremembé (SF.23-Y-B-V-4), Taubaté (SF.23-Y-D-II-2) e Pindamonhangaba (SF.23-Y-B-VI-3), escala 1:50.000, Estado de São Paulo. São Paulo, Relatório IPT n 28732, ilustrações/fotos/mapas. 
IPT-INSTITUTO DE PESQUISAS TECNOLÓGICAS DO ESTADO DE SÃO PAULO (1981). Mapa geomorfológico do Estado de São Paulo, escala 1:1.000.000. São Paulo, Relatório IPT n 1183, Vol.1.

Macedo, Eduardo S., Ogura, Agostinho T., Santoro, Jair (1999). Defesa civil e escorregamentos: o plano preventivo do litoral paulista. Congresso Brasileiro de Geologia de Engenharia e Ambiental, 9, 1999, São Pedro, Anais eletrônicos, CD-ROM.

Macedo, Eduardo S., Ogura, Agostinho T., Santoro, Jair (2006). O que é um plano de contingência ou plano preventivo de defesa civil. In: Carvalho, C.S. e Galvão, T. (Org.) Prevenção de Riscos de Deslizamentos em Encostas: Guia para elaboração de políticas municipais, Ministério das Cidades/Cities Alliance, Brasília, p. 78-91.

Macedo, Eduardo S., Santoro, Jair, Cerrl, Leandro E. S., Ogura, Agostinho T. (2002). Plano preventivo de defesa civil (PPDC) para escorregamentos no trecho paulista da Serra do Mar, SP. In: Santos, A.R. (Org.) - Geologia de Engenharia: conceitos, método e prática, ABGE/IPT, São Paulo, $1^{\text {a }}$ ed., vol.1, p. 42-46.

Nery, J. T., Vargas, W. M., Martins, M. L. O. F. (1999). Estrutura da precipitação do Estado de São Paulo. Revista Brasileira de Recursos Hídricos, vol.4/n. ${ }^{\circ} 4$, Porto Alegre, p.51-61.

Nilsen, T. H., Turner, B. L. (1975). Influence of rainfall and ancient landslide deposits on recent landslides (1950-71) in urban areas of Contra Costa County, California: U.S. Geological Survey, Bulletin 1388.

Nunes, A. J. C. (1969). Landslides in soils of decomposed rock due to intense rainstorms. International Conference on Soil Mechanics and Foundations Engineering, 7, 1969, Mexico, Proceedings, vol.2, pp. 547-554.

Oliveira, J. B. (1999). Solos do Estado de São Paulo: descrição das classes registradas no mapa pedológico, Boletim Científico $n^{\circ} 45$, Campinas: Instituto Agronômico de Campinas, $108 p+4$ mapas.

Parizzi, M. G., Sebastião, C. S., Viana, C. S., Pflueger, M. C., Campos, L. C., Cajazeiro, J. M. D., Tomich, R. S., Guimarães, R. N., Abreu, M. L., Sobreira, F. G., Reis, R. (2010). Correlações entre chuvas e movimentos de massa no município de Belo Horizonte, MG. Geografias, vol. 06/n. ${ }^{\circ}$ 2, Belo Horizonte, p. 49-68. Disponível em http:// www.cantacantos.com.br/revista/index.php/ geografias/article/view/117
Perrella, A. C. F., Ferreira, M. E. (2002). Um estudo sobre as inundações em São José dos CamposSP. Congresso Brasileiro de Meteorologia, 12, 2002, Foz do Iguaçu, Anais eletrônicos, CDROM, p. 1798-1814.

Pichler, E. (1957). Aspectos geológicos dos escorregamentos de Santos. Boletim da Sociedade Brasileira de Geologia, vol. 6/n. ${ }^{\circ}$ 2, São Paulo, p. 69-77.

PMSJC-PREFEITURA MUNICIPAL DE SÃO JOSÉ DOS CAMPOS (2006). Plano Diretor de Desenvolvimento Integrado Diagnóstico, PMSJC/SJC. Disponível em http:// www.sjc.sp.gov.br/media/24560/2006_pd_ diagnostico.pdf. [Acessado em 11/11/2014].

PMSJC-PREFEITURA MUNICIPAL DE SÃO JOSÉ DOS CAMPOS (2013). Diagnóstico das áreas de risco a escorregamentos no município de São José dos Campos/SP. Relatório Interno da Defesa Civil Municipal, PMSJC/SJC, 45p+mapas.

Quinta Ferreira, M., Lemos, L. J. L., Pereira, L. F. M. (2005). Influência da Precipitação na ocorrência de deslizamentos em Coimbra, nos últimos 139 anos. Revista Portuguesa de Geotecnia, n 104, Lisboa, p. 17-30.

Santoro, Jair, Mendes, Rodolfo M., Pressinotti, Marcia M. N., ManoeL, Gisele dos Reis (2010). Correlação entre chuvas e deslizamentos ocorridos durante a operação do plano preventivo de defesa civil em São Paulo, SP. Simpósio Brasileiro de Cartografia Geotécnica e Ambiental, 7, 2010, Maringá, Anais eletrônicos, CD-ROM, p.1-15.

Tatizana, C., Ogura, Agostinho T., Cerri, Leandro E. S., Rocha, M. C. M. (1987a). Análise da correlação entre chuvas e escorregamentos na Serra do Mar, município de Cubatão. Congresso Brasileiro de Geologia de Engenharia, 5, 1987, São Paulo, Anais impressos, v.2, p. 225-236.

Tatizana, C., Ogura, Agostinho T., Cerri, Leandro E. S., Rocha, M. C. M. (1987b). Modelamento numérico da análise de correlação entre chuvas e escorregamentos aplicado às encostas da Serra do Mar no município de Cubatão. Congresso Brasileiro de Geologia de Engenharia, 5, 1987, São Paulo, Anais impressos, v. 2, p. 237-248.

Valério Filho, Mário, Mendes, Rodolfo M., Faria, Daniela G. M., Fantin, Marcel, Bertoldo, Mathilde A., Melo, Fábio N., Silva, Marlon F., Cunha, Ricardo P. (2014). Mapeamento das áreas de riscos associados a escorregamentos de encostas no município de São José dos Campos$S P$. Relatório Técnico Final, Convênio UNIVAP/ PMSJC, Processo n 53.366/2013, São José dos Campos, 60p+anexos. 